\title{
The use of a metabolic disorder index as a predictor for metabolic eliminations in endurance horses
}

\begin{abstract}
The equine endurance race involves both aerobic and anaerobic metabolisms of the horse. The intense physical activity over an extended period often causes susceptible horses to develop metabolic signs or problems resulting in elimination from races. Thus, the objective of this study was to develop a method for prediction and validation of a metabolic disorder index (MDI) to be used before endurance races. Three hundred seventy-five Arabian ( $\mathrm{n}=$ 152) and Arabian cross $(n=223)$ endurance horses aged from 6 to 15 years and weighing between 350 and $450 \mathrm{~kg}$ were selected for the study in Malaysia. Blood samples were collected at pre- and post-race periods. The significant $(\mathrm{P}<.05)$ findings in horses with metabolic disorder were packed cell volume $(0.50 \pm 0.06 \mathrm{LL}-1)$, creatine kinase $(1,275.89 \pm$ $121.45 \mathrm{UL}-1)$, interleukin-6 $(2.01 \pm 0.89 \mathrm{ng} / \mathrm{mL})$, decreased glutathione reductase $(26.57 \pm$ $3.95 \mathrm{ng} / \mathrm{mL})$, and chloride $(94.98 \pm 8.12 \mathrm{mmol} / \mathrm{L})$. A new method called MDI was developed as a predictor for horses with the potential to develop metabolic disorders in endurance races. The MDI indicated a higher value greater than 5.5 for those eliminated and lower value below 5.5 for those that completed the race successfully, this proved to be accurate in the prediction of metabolic disorder in endurance horses. The MDI is an innovative and simple method used as a prediction method that will assist the equine endurance society to reduce the rate of elimination and to safeguard against serious medical problems during endurance races in the tropics.
\end{abstract}

Keyword: Metabolic disorder index; Predictor; Endurance horse 